\title{
ESTIMATIVA DA VULNERABILIDADE NATURAL À CONTAMINAÇÃO DO AQUÍFERO NO MUNICÍPIO DE SÃO SEPÉ- RS
}

Estimated natural vulnerability aquifer contamination in São Sepé district- $R S$

\author{
Lueni Gonçalves Terra ${ }^{1}$, Bruna Nascimento de Vasconcellos Schiavo², Gabriel \\ D'Avila Fernandes $^{1}$, Willian Fernando de Borba ${ }^{1}$, José Luiz Silvério da Silva ${ }^{1}$ \\ ${ }^{1}$ Universidade Federal de Santa Maria (Laboratório de Hidrogeologia - LABHIDROGEO) \\ 2 Universidade Federal do Paraná
}

\begin{abstract}
Resumo
Em consequência ao aumento significativo da urbanização e do incremento de serviços necessários ao suprimento da população, cresce a utilização de águas subterrâneas para suprir diversos usos. A partir disso, os estudos de vulnerabilidade do aquífero a contaminação tornam-se uma importante ferramenta. O presente estudo tem por objetivo principal mapear a vulnerabilidade das águas subterrâneas do município de São Sepé-Rio Grande do Sul, localizado no sul do Brasil, situado no escudo Uruguaio Sul Rio-Grandense, aquífero cristalino fissural. Para a espacialização foi utilizado o método GOD, adaptado para as condições brasileiras. Para tanto elaborou-se um banco de dados hidrogeológicos relativos a 8 captações que continham as informações necessárias à aplicação do método (grau de confinamento, meio aquífero e profundidade do nível da água). O cartograma da vulnerabilidade apontou que a classe predominante foi a baixa, equivalente a 44,56\% do total da área, seguida da classe média representada por 39,33\% e da classe alta com 12,91\% mapeado. As classes extrema e insignificante representaram 2,78\% e 0,42\% respectivamente. Esses resultados apontam a necessidade de indices de vulnerabilidade a serem considerados em licenciamento de empreendimentos potencialmente poluidores e na implantação de planos diretores.
\end{abstract}

Palavras-chave: Aquífero. Vulnerabilidade. Gestão. GOD.

Abstract

As a result of the significant increase in urbanization and the need to supply the population service increase gradually grows the use of groundwater to meet different uses.Based on this, the studies of the aquifer vulnerability to contamination becomes an important tool. This study aims to map the vulnerability of groundwater in Sao Sepe-Rio Grande do Sul, southern Brazil, which is located in the Uruguayan South Rio-Grandense shield, fractured crystalline aquifer. For the spatialization the method used was GOD, adapted to the Brazilian conditions. Then, a hydrogeological database was elaborated for the eight funding containing the necessary information for the method (degree of containment, middle aquifer and deep water level). The vulnerability cartogram pointed out the predominant class such as low, equivalent to $44,56 \%$ of the total area, followed by the middle class represented by 39,33\% and the high class with $12,91 \%$ mapped. The extreme and insignificant classes represented $2,78 \%$ and $0,42 \%$ respectively. These results highlight the need for vulnerability indices, which should be considered for the licensing of potentially polluting enterprises and implementation of master plans.

.Keywords: Aquífer. Vulnerability. Management. GOD. 


\section{Introdução}

Segundo Mucelin e Bellini (2008) a criação das cidades e a ampliação das áreas urbanas têm contribuído para a geração de impactos ambientais negativos. Wolkmer et al. (2013) salientam que todos os problemas responsáveis por alterar a qualidade do meio ambiente atingem em primeiro lugar a água. Isso faz com que estudos sobre os recursos hídricos e o meio sejam importantes para o desenvolvimento sustentável.

Dambrós et al. (2010) salientam que a falta de informações e o manejo inadequado das reservas hídricas subterrâneas podem atingir níveis siginificantes de contaminação. Principalmente devido ao alto custo de recuperação dos aquíferos, a prevenção às contaminações torna-se a alternativa mais viável.

Foster et al. (2006), consideram que o mapeamento da vulnerabilidade do aquífero à contaminação representa, geralmente, o primeiro passo na avaliação do risco de contaminação da água subterrânea e na proteção de sua qualidade em escala municipal ou estadual. Sobre o conceito de vulnerabilidade, Foster (1987) definiu como sendo o conjunto de características intrínsecas dos estratos entre a zona saturada e a superfície do solo, é o que determina sua susceptibilidade a sofrer efeitos adversos de uma carga contaminante que é, será ou pode ser aplicada na região acima do nível freático.

Ribeiro (2005) discorre sobre índices de vulnerabilidade: “A grande maioria dos métodos de avaliação da vulnerabilidade possuem uma natureza empírica, o que é veículo para o surgimento de um vasto leque de diferentes interpretações por diferentes técnicos. Essa subjetividade vai repercutir forçosamente na atribuição de valores numéricos a entidades de natureza descritiva". Na opinião do autor torna-se necessário distinguirem-se dois tipos de vulnerabilidade: a intrínseca e a específica. A intrínseca considera unicamente as características geológicas, hidrológicas e hidrogeológicas do meio, sendo por isso independente do tipo de poluente gerado pelas atividades antropogênicas.

Já a vulnerabilidade específica deve ser utilizada sempre que se consideram também as propriedades de um poluente específico e as suas relações com os componentes de vulnerabilidade intrínseca. Neste trabalho, foi considerada a vulnerabilidade como sendo intrínseca.

Foster et al. (2013) consideram que a vulnerabilidade do aquífero se destina a representar a variação do nível de proteção natural ou a capacidade de atenuação do contaminante na zona de solo insaturado ou zona de semi-confinamento da água, localizadas acima do aquífero. Essa contaminação advém de processos físicos e químicos (filtração, biodegradação, hidrólise, adsorção, neutralização, e volatilização dispersão).

Nesse sentido e diante da carência de estudos desse gênero a nível municipal, o presente trabalho objetivou desenvolver um mapeamento de vulnerabilidade intrínseca à contaminação natural dos recursos hídricos subterrâneos do município de São Sepé- RS, a fim de fornecer uma ferramenta importante para os órgãos responsáveis pela gestão das reservas subterrâneas em escala municipal.

\section{Metodologia}

\subsection{Localização e caracterização da área de estudo}

O município de São Sepé, localiza-se na região central do estado do Rio Grande do Sul, sob as coordenadas geográficas de $30^{\circ} 09^{\prime} 38^{\prime \prime}$ sul de latitude e a uma longitude 533' $55^{\prime \prime}$ oeste de Greenwich, conforme pode ser observado na figura 01. Situa-se, de acordo com a divisão do Instituto Brasileiro de Geografia e Estatística (IBGE, 2008), na microrregião de Santa Maria e na mesorregião Centro Ocidental Rio-Grandense. O censo demográfico do IBGE (2010) aponta o município com um total de 23.198 habitantes, sendo que 18.821 habitantes do meio urbano e 4.377 habitantes do meio rural. 
Segundo Scherer (2009), destaca-se o setor agropecuário como uma das principais atividades desenvolvidas no município.

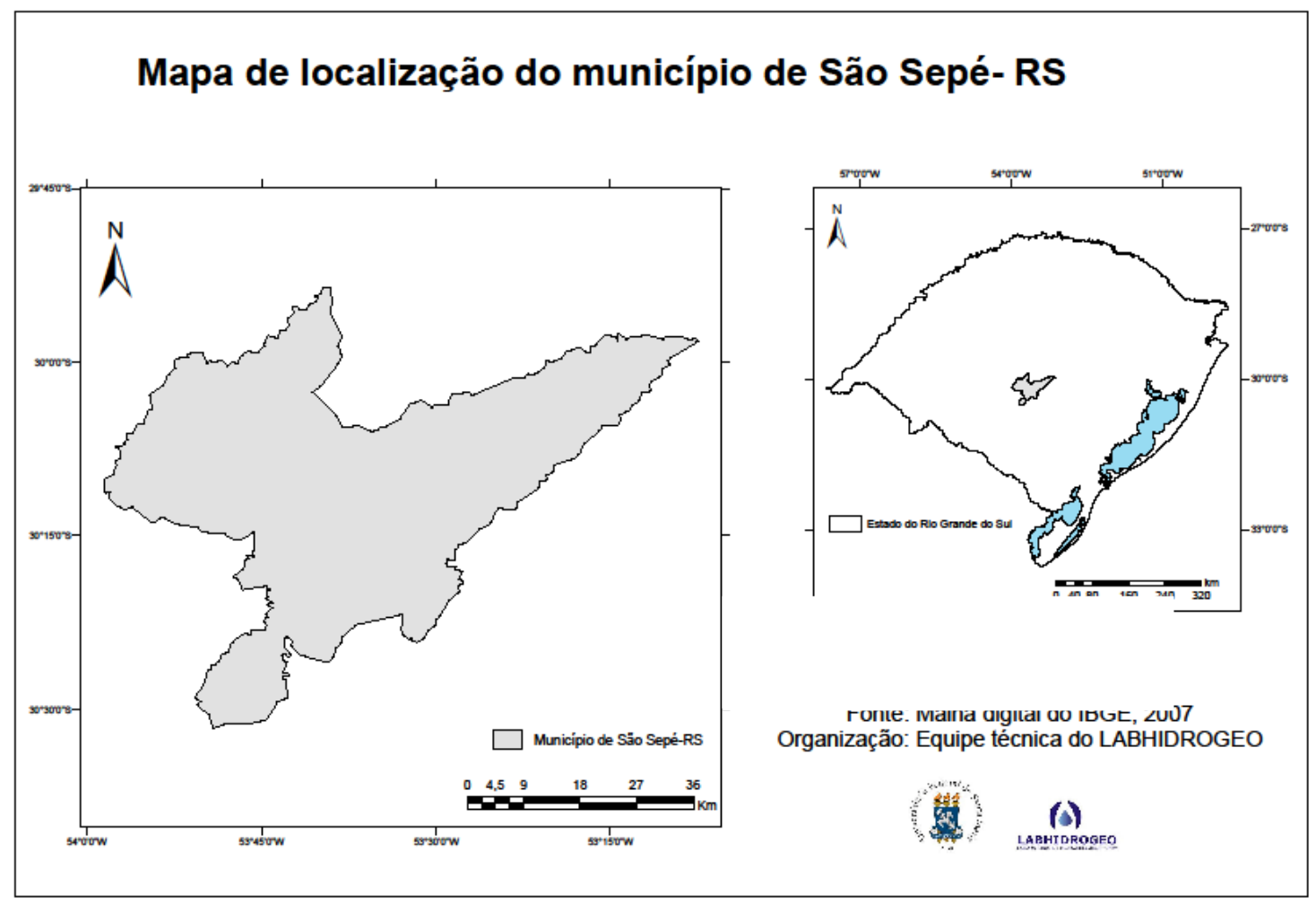

Figura 1- Localização do município de São Sepé no estado do Rio Grande do Sul

\subsection{Obtenção de dados}

Para a realização do presente estudo foi organizado um banco de dados com as informações disponíveis no sítio do Sistema de Informações de Águas Subterrâneas (SIAGAS), mantido pela Companhia de Pesquisa de Recursos Minerais (CPRM,) para o município de São Sepé- RS. Foram elencadas as informações de interesse de treze poços cadastrados. Porém, apenas oito foram selecionados para a pesquisa, porque apresentaram as informações necessárias para análise.

\subsection{Determinação da vulnerabilidade natural à contaminação pelo sistema GOD}

O sistema GOD descrito em Foster et al. (2006), leva em consideração os parâmetros G (Grau de confinamento hidráulico da água subterrânea/aquífero), O (Ocorrência de estratos de cobertura) e D (Profundidade/distância até o lençol freático). Sendo assim, para a determinação do índice de vulnerabilidade, seguiram-se as etapas ilustradas na Figura 2.

O índice de vulnerabilidade é obtido a partir do produto das variáveis GOD, sendo assim obtém-se a vulnerabilidade natural do aquífero a contaminação, a qual pode ser classificada como de classe insignificante (valores entre 0 e 0,1$)$, baixa $(0,1$ e 0,3$)$, média $(0,3$ e 0,5$)$, alta $(0,5$ e 0,7$)$ e extrema $(0,7$ e 1$)$ conforme tabela 1 . Os resultados foram especializados em mapas temáticos. 


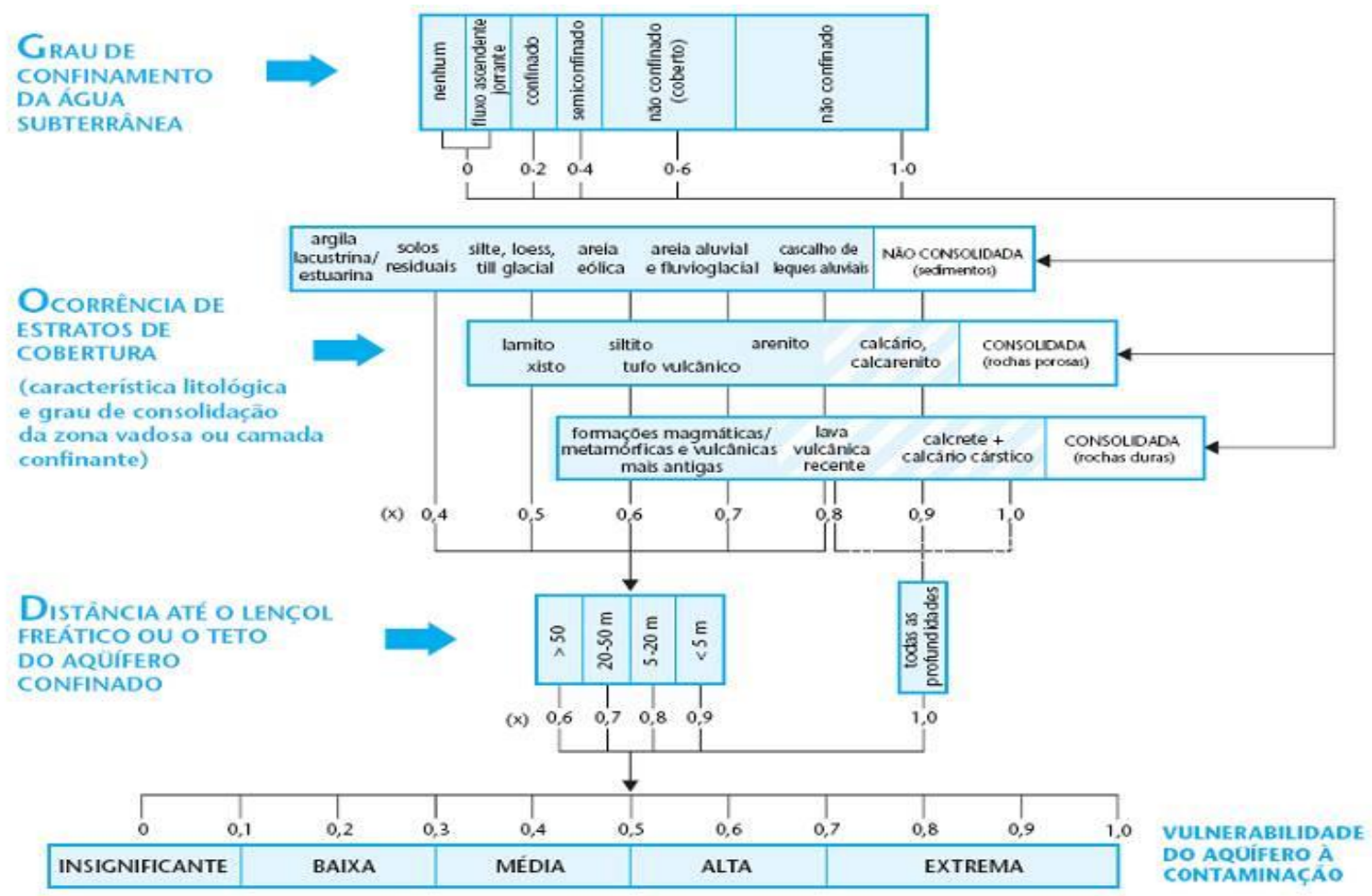

Figura 2- Etapas necessárias para a determinação da vulnerabilidade pelo sistema GOD Fonte: Foster et al. (2006)

Tabela 1 - Classes de vulnerabilidade obtidas pelo Sistema GOD (Foster et al., 2006).

\begin{tabular}{|c|c|}
\hline $\begin{array}{c}\text { Classe de } \\
\text { vulnerabilidade }\end{array}$ & Caracteristica \\
\hline Extrema & Vulnerável à maioria dos contaminantes com impacto rápido em muitos cenários de contaminação \\
\hline Alta & $\begin{array}{l}\text { Vulnerável a muitos contaminantes (exceto os que são fortemente adsorvidos ou rapidamente } \\
\text { transformados) em muitas condições de contaminação }\end{array}$ \\
\hline Moderada & Vulnerável a alguns contaminantes, mas somente quando continuamente lançados ou lixiviados \\
\hline Baixa & $\begin{array}{l}\text { Vulnerável somente a contaminantes conservadores, a longo prazo, quando contínua e amplamente } \\
\text { lançados ou lixiviados }\end{array}$ \\
\hline Insignificante & Presença de camadas confinantes sem fluxo vertical significativo de água subterrânea (percolação) \\
\hline
\end{tabular}

\subsection{Espacialização dos dados}

Os mapas foram elaborados dentro de ambiente SIG (Sistema de Informação Geográfica) com uso do programa ArcGIS 10. A delimitação da área foi feita a partir de shape disponibilizado pelo IBGE (2005). Para interpolar os dados foi usado o IDW (InverseDistanceWeighting), o qual na comparação com outros interpoladores foi o que melhor representou a realidade dos dados. Foi usado o sistema de coordenadas UTM (Universal Transversa de Mercator) com o Datum horizontal SAD 69 e o Datum Vertical o Porto de Imbituba/Santa Catarina.

\section{Resultados}

No que tange à geologia (Figura 02), com base no mapa geológico do Estado do Rio Grande do Sul (CPRM, 2008), o município possui grande diversidade de afloramentos em seu território, sendo que na porção norte há predomínio de Depósitos Aluviais (Q4a), Formação Sanga do Cabral (T1sc), Formação Rio do Rasto (P3T1rr), Subgrupo Estrada Nova (P23en). Na porção sul há predomínio de 
uma sequência sedimentar e vulcânica (NP3_gamma_cc), Granito São Sepé (NP3_gamma_ss), Complexo Metamórfico Vacacaí-unidade vulcânica (NP2vcv) e presença de Depósitos Aluviais. Com isso, o município possui as formações descritas abaixo (CPRM, 2008):

-Formação Acampamento Velho (NP3alfaav): Vulcanismo bimodal de característica alcalino, constituído por derrames de riolitos alcalinos e peralcalinos;

- Formação Acampamento Velho (NP3alfaavp): com depósitos de fluxos piroclásticos, brechas, tufos, tufos lapilíticos e ignimbritos;

Fácies $\quad$ Básicas $\quad$ Constituída por derrames andesíticos, traquitos, basaltoos mugearíticos e depósitos básicos, acompanhando de intrusivas representadas por diques de sienitos e monzodioritos;

- Fácies Coerente (NP3 beta hic): Contendo derrames de traquibasaltos a traquiandesitos, sucedendose andesito, localmente dacito e intrusivas representadas por domos de lamprofilos espessartiticos e necks de monzonitos e quartzomonzonitos;

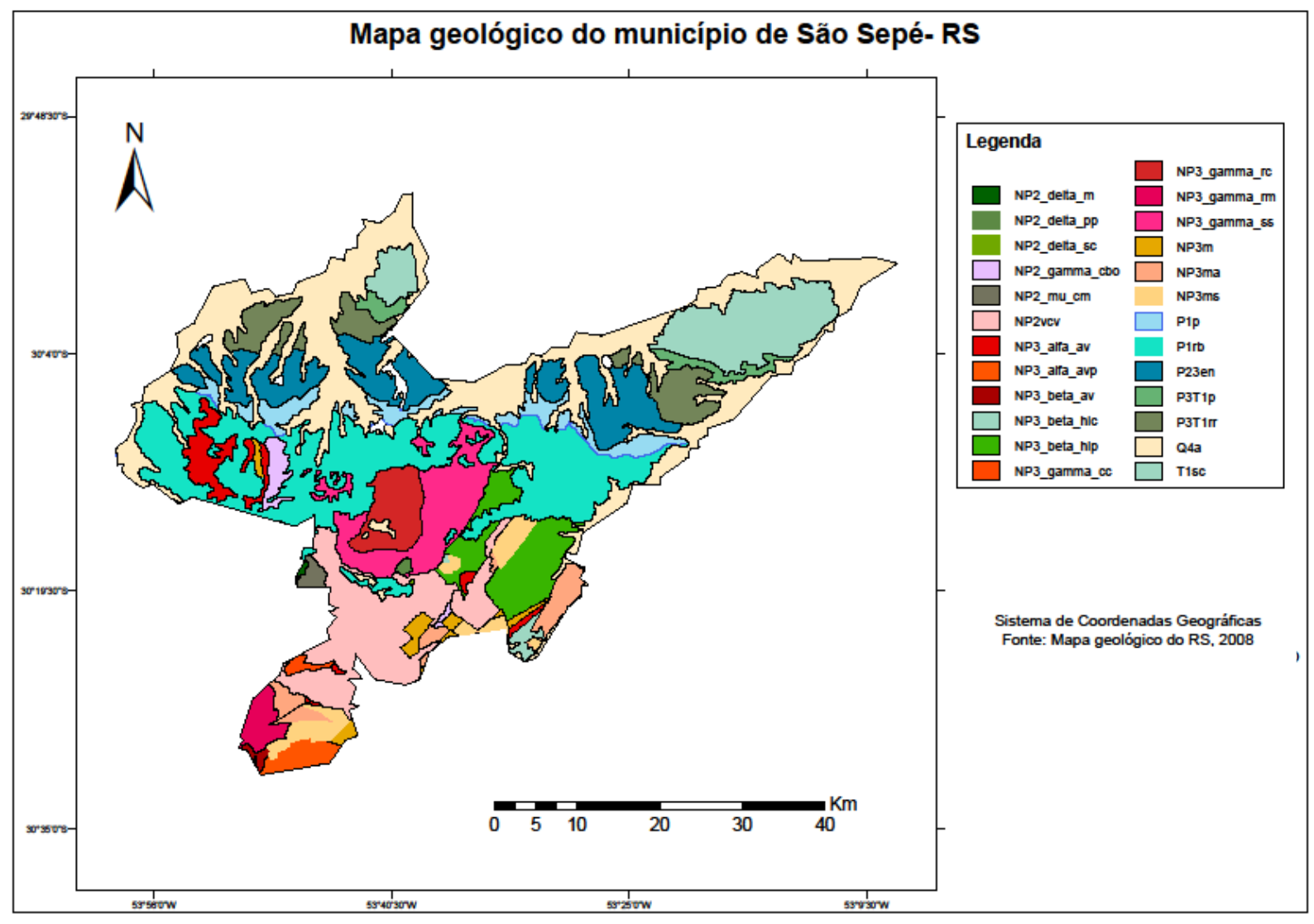

- Fácies Particulada (NP3 beta hip): onde intercalam-se aos derrames, depósitos piroclásticos relacionados a queda e fluxo, com tufos lapilíticos, tufos, brechas e igmimbritos, seguidos de depósitos sedimentares vulcanogênicos.

- Manzogranito Rincão dos Coqueiros (NP3 gama rc): manzogranito e granodiorito equinogranulares a porfiríticos médios com textura papakivi;

- Granito Cerro da Cria (NP3 gama cc): Pertilogranito a localmente sienogranito;

- Granito Ramada (NP3 gama rm):sieno a monzogranito granular médio;

- Granito São Sepé (NP3 gama ss): sierogranito de epizona, com cavidades miarolíticas;

- Formação Passo da Promessa (NP3 m): Arenito e lentes conglomeráticas formadas em planícies fluviais de canais entrelaçados;

- Formação Arroio América (NP3ma): Arenitos e lentes conglomeráticas registrando novo sistema de planícies fluviais de canais entrelaçados; 
- Formação São Rafael (NP3ms): Arenito e ritmitos de plataforma marinha rasa dominada por ondas tempestitos - associadas a turbiditos areno - peliticos da costa afora;

- Gabro Mata Grande (NP2 delta m): gabro de granulação fina a grossa de composição troctolítica e rochas ultrabásicas subordinadas;

- Maciço de Pedras Pretas (NP2 delta pp) e Grupo Santa Catarina (NP2 delta sc): Gabro, leucograbo e anortosito interacamados com ultrabásicas supertinizada. Estruturas magmáticas preservadas. Metamorfismo transicional entre as fácies xisto verde e anfibolito;

- Complexo Cambaí - Domínio de Ortognaisses (NP2 gama cbo): Onde predominam gnaisses monzogranítico, granodiorítico, tonalítico e trondhjemítico, contendo enclaves de anfibolitos, metaultrafitos e matagrabros;

- Complexo Máfico - Ultramáfico Cerro Mantiqueira (NP2 mi cm): metamafito, metagrabo, serpentinito, xisto magnesiano e ortoanfibolito;

- Complexo Metamórfico Vacacaí - Unidade Vulcânica (NP2vcv): metandesito, metatufo, metavulclanoclástica e níveis de sedimentos vulcanogênicos metamorfizados nas fácies xisto verde e anfibolito cristalino da bacia sedimentar do Paraná;

- Formação Palermo (P1p): Siltito, siltito arenoso, arenito fino e folhelho, lentes de arenito grosso com seixos discóides, ambiente marinho de costa-afora com influência de tempestades;

- Formação Rio Bonito (P1rb): arcóseo, siltito carbonoso e quartzoarenito, folhelho carbonoso e carvão, tonstein, diamictito com matriz carbonosa e marga, ambiente flúvio-deltáico, litorâneo e marinho plataformal;

- Subgrupo Estrada Nova (P23en): folhelho, argilito e siltito não betuminosos, ambiente marinho com deposição por decantação de finos abaixo do nível-base de ação das ondas (Formação Serra Alta). Siltito, arenito, muito fino, geralmente tabular ou lenticulado alongado, lentes e concreções de calcário, ambiente marinho com influência de tempestades (Formação Teresinha);

- Formação Pirambóia (P3tip): arenito médio a fino, geometria lenticular bem desenvolvida, ambiente continental, eólico com intercalação fluviais;

- Formação Rio do Rasto (P3T1rr): Pelito e arenito com dominância de camadas tabulares ou lenticulares muito estendidas, ambiente lacustre (Membro Serrinha); siltito tabular, arenito fino tabular ou lenticular, ambiente lacustre deltaico, eólico e raros depósitos fluviais (Membro Morro Pelado);

- Depósitos Aluviais (Q4a): Areia grossa a fina, cascalho e sedimento síltico-argiloso, em calhas de rio e planícies de inundação e;

- Formação Sanga do Cabral (T1sc): Em corpos tabulares ou lenticulares alongados, brecha e conglomerado intraformacional, siltito e raro argilito, ambiente continental, fluvial entrelaçado, contendo localmente fragmentos de vertebrados fósseis (anfíbios e répteis).

Assim reunindo-se todas litologias formadas por rochas cristalinas formadoras de aquíferos fissurais foram reunidas no Sistema Aquífero Cristalino I (ec1) e Sistema Aquífero Cristalino II (ec2). Quando essas formações geológicas contem água subterrânea formam Unidades Hidroestratigráficas, e quando estão interconectadas formam os Sistemas Aquíferos.

A Figura 3 ilustra a vulnerabilidade natural a contaminação do aquífero no município de São Sepé-RS. Verifica-se que todas as classes de vulnerabilidade foram encontradas na área estudada.

Além disso, pode-se observar (em vermelho) que a região norte do município apresenta as classes de vulnerabilidade alta e extrema. Isso ocorre porque, na área, há predomínio de depósitos aluviais e formação Sanga do Cabral.

As classes de vulnerabilidade consideradas menores (média, baixa e insignificante) foram encontradas nas demais áreas do Município. Isso está relacionado ao predomínio de sequência sedimentar e vulcânica, granito São Sepé, complexo metamórfico vacacaí-unidade vulcânica e presença de depósitos aluviais nas porções mais ao sul.). Assim, apontando que a vulnerabilidade natural à contaminação do aquífero está fortemente atrelada à formação geológica local.

Visualiza-se ainda que, a classe baixa foi predominante na área avaliada, destacada na cor mais clara do mapa (bege), porém, as classes de média e alta também foram representativas. A classe de vulnerabilidade extrema, visualizada em vermelho, ao extremo noroeste do município, em área 
susceptível geologicamente (depósitos aluviais) indica e sugere o cuidado que o poder público deve ter com a localização de empreendimentos potencialmente poluidores, principalmente nesse local.

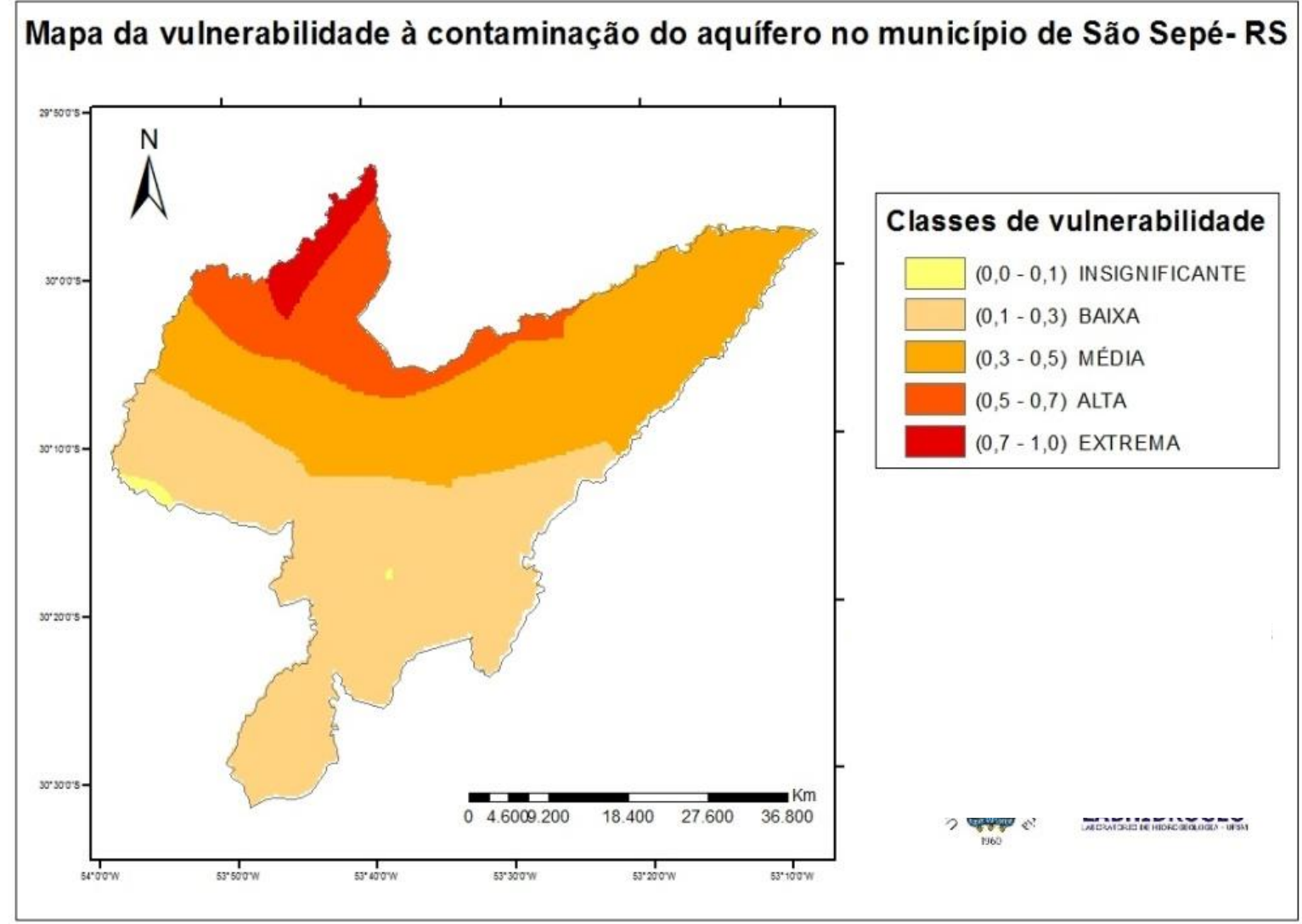

Figura 3- Vulnerabilidade natural à contaminação do aquífero no município de São Sepé-RS

A partir da análise da área de cada classe de vulnerabilidade interpolada (Tabela 2) pode-se inferir que apesar da maior área $(44,56 \%$ do total), representar a classe de baixa, seguida da classe média, com uma área de $849,17 \mathrm{~km}^{2}(39,33 \%)$ há uma área elevada mapeada com vulnerabilidade alta, aproximadamente $278,83 \mathrm{~km}^{2}(12,91 \%)$. A classe extrema e a insignificante representaram 60,075 e $8,80 \mathrm{~km}^{2}$, respectivamente e indicam áreas pontuais de localização e de menores expressões na área de estudo.

Tabela 2- Áreas referentes as classes de vulnerabilidade na área de estudo, São Sepé-RS

\begin{tabular}{ccc}
\hline Classe & Área( $\mathbf{K m}^{2} \mathbf{2}$ & Percentual(\%) \\
\hline Insignificante & 8,80 & 0,42 \\
\hline Baixa & 962,19 & 44,56 \\
\hline Média & 849,17 & 39,33 \\
\hline Alta & 278,83 & 12,91 \\
\hline Extrema & 60,07 & 2,78 \\
\hline Total & 2159,09 & 100,00 \\
\hline
\end{tabular}




\section{Conclusão}

O manejo inadequado e à falta de informações torna necessário estudos que viabilizem um melhor gerenciamento das reservas subterrâneas. Assim, as espacializações de vulnerabilidade à contaminação de aquífero apresentam-se como uma importante ferramenta para a minimização de impactos ambientais negativos. Afinal, apontam áreas que devem ser mais protegidas, quanto ao desenvolvimento de atividades com maior potencial de poluição.

A apreciação dos resultados consente dizer que o município de São Sepé possui a maioria das captações de águas subterrâneas localizadas em áreas de baixa e média vulnerabilidade. Esse resultado deve ser considerado no uso e ocupação do solo, principalmente na construção e implantação do plano diretor municipal.

\section{Referências}

ASSOCIAÇÃO BRASILEIRA DE ÁGUAS SUBTERRÂNEAS, ABAS. Disponível em: $<$ http://www.abas.org/educacao.php\#ind21>. Acesso em: 22. dez. 2013.

CONSELHO NACIONAL DE RECURSOS HÍDRICOS (Brasil). Resolução n. 15, de 11 de janeiro de 2001. Estabelece diretrizes para a gestão das águas subterrâneas. Disponível em: $<$ http://www.cnrh.gov.br/index.php?option=com_content\&view=article\&id=14>. Acesso em: 22.dez.2013.

COMPANHIA DE PESQUISA DE RECURSOS MINERAIS, CPRM. Sistema de Informações de Águas Subterrâneas, SIAGAS. Banco de dados dos poços cadastrados em São Sepé-RS. Disponível em: <<http://siagasweb.cprm.gov.br/layout/pesquisa_complexa.php >. Acesso em: 20 dez. 2013.

DAMBRÓS C.; SILVÉRIO DA SILVA, J. L.; DESCOVI FILHO, L. L. V. Aproximando ideias e construindo reflexões na busca da sustentabilidade das águas subterrâneas. In: XVI CONGRESSO BRASILEIRO DE ÁGUAS SUBTERRÂANEAS E XVII ENCONTRO NACIONAL DE PERFURADORES DE POÇOS. 2010. Anais... São Luís do Maranhão. 2010.

FOSTER, S. S. D. Fundamental concepts in aquifer vulnerability, pollution risk and protection strategy. In: Vulnerability of Soil and Groundwater to Pollutants, 38., 1987, Noordwijk. Proceedings and Information of the International Conference held in the Netherlands. Noordwijk: TNO Committee on Hydrological Research, 1987. p. 69-86.

FOSTER, S. HIRATA, R.; ANDREO, B. The aquifer pollution vulnerability concept: aid or impediment in promoting groundwater protection? Hydrogeology Journal. v 21, n 7, p. 1389-1392, 2013.

FOSTER, S. HIRATA, R.; GOMES, D.; D’ELISA, M. Proteção da qualidade da água subterrânea: um guia para empresas de abastecimento de água, órgãos municipais e agências ambientais. São Paulo: Servemar. 2006.

INSTITUTO BRASILEIRO DE GEOGRAFIA E ESTATÍSTICA. IBGE - Instituto Brasileiro de Geografia e Estatística. Disponível em: <http://www.ibge.gov.br>. Acesso em: 22. dez. 2013.

MACHADO, J. L. F. Compartimentação espacial e arcabouço hidroestratigráfico do Sistema Aquifero Guarani no Rio Grande do Sul. 2005. 237f. Tese (Doutorado em Geologia) - Universidade do Vale do Rio dos Sinos, São Leopoldo, 2005. Disponível em: < http://www.cprm.gov.br/publique/media/aquifero.pdf $>$. Acesso em: 17.mar.2014.

MACHADO, J. L. F.; FREITAS, M. A. Projeto Mapa Hidrogeológico do RS. Porto Alegre: Convenio SOPS/SEMA/DRH/CPRM. 2005.

MUCELIN, C. A; BELLINI, M. Lixo e impactos ambientais perceptíveis no ecossistema urbano. Sociedade \& Natureza, Uberlândia, 20 (1): p. 111-124. 2008. 
RIBEIRO, L. F. T. Um novo índice vulnerabilidade específico de aquíferos: formulação e aplicações. In: SIMPÓSIO DE HIDRÁULICA E RECURSOS HÍDRICOS DOS PAÍSES DE LÍNGUA OFICIAL PORTUGUESA (SILUSBA), 7., 2005, Évora. Anais... Évora, 2005. p. 16.

SCHERER, F. B. Construção do espaço urbano da pequena cidade: um estudo sobre São Sepé-RS. 2009. 102f. Dissertação (Mestrado em Geografia) - Universidade Federal de Santa Maria, Santa Maria. 2009.

WOLKMER M. DE F. S.; SCHEIBE L. F.; HENNING L. A. A rede Guarani/Serra Geral: um projeto em movimento. Disponível em: < https://rgsgsc.files.wordpress.com/2013/11/artigo_livro_rgsg.pdf $>$. Acesso em: 23. dez. 2013. 